\title{
Effects of Smoking Habit on the Development of Tuberculosis Disease
}

\author{
Lasmaria Magdalena Hutahaean \\ Public Health Community Medical Center Tiga panah,Kab karo Indonesia
}

\begin{abstract}
Abtract: Smoking and tuberculosis (TB) are two major problems of health in the world, even though TB is mostly found in developing countries. After HIV and AIDS spread, TB is the leading cause of death worldwide and is responsible for more than one million deaths every year. The data of World Health Organization (WHO) show that Indonesia becomes the $3^{\text {rd }}$ biggest country of smoker rate after China and India, followed by Russia and United States. Whereas, according to the total population, Indonesia is in the 4th position after China, India, and United States. The aim of this research is to analyze the effects of smoking habit on the development of tuberculosis disease. From the analysis result show: (1) Smoking and TB remain a significant health problem in both developed countries and developing countries, (2) Cigarette smoke has the effects of both proinflammatory and immunosuppressive in the immune system of respiratory tract, (3) Smoking increases the infection risk of Mycobacterium tuberculosis, the risk of disease progression and death in patients with TB, (4) Quitting smoking plays a role in global tuberculosis control and reduces mortality in patients with TB.

Keywords: Smoking Habit, Tuberculosis, Mortality
\end{abstract}

\section{Introduction}

Smoking and tuberculosis (TB) are two major problems of health in the world, even though TB is mostly found in developing countries. After HIV and AIDS spread, TB is the leading cause of death worldwide and is responsible for more than one million deaths every year. The using of tobacco especially for smoking has been known as one of the most common problems that has been widely recognized by society. It also becomes one of the most dangerous factors that triggers death in the world, which was about 1.7 million in 1985, 3 million in 1990 and it is projected that it will increase up to 8.4 million in 2020 [1]. The total of smokers in the world have increased dramatically. Now, approximately there are 3 billion of smokers and it will increase to 1.7 billion smokers in 2025 . Around $65-85 \%$ of tobacco has been consumed all over the world form cigarettes and it has led to mortality every second [2].

The data of World Health Organization (WHO) show that Indonesia becomes the $3^{\text {rd }}$ biggest country of smoker rate after China and India, followed by Russia and United States. Whereas, according to the total population, Indonesia is in the 4th position after China, India, and United States. It is different with smokers in United States which tend to decrease, the smokers in Indonesia indeed have increased in the recent 9 years. Growth of smokers in Indonesia in the period of 2000-2008 was 0.9\% every year. There are many diseases which are connected with smoking such as arthritic, impotence, infertility, Alzheimer, TB, and so on [2,3]. The lung is an organ that suffers the most due to smoking habit. The relationship between smoking and TB was firstly reported at the beginning of the 20nd century. Even though the exact mechanism has been known yet, there have been many researches discussing the relationship between smoking and TB [4]. The aim of this research is to analyze the effects of smoking habit on the development of tuberculosis disease

\subsection{Smoking}

\section{Theoretical Review}

Tobacco was introduced in Indonesia by Netherland about 2 centuries ago and the using of tobacco by Indonesian was when the local elite of Indonesia tried to copy the habit of Dutch people that was then followed by lower class people. They replaced it by chewing betel, and this became the habit of Indonesian people. The word of rokok (cigarettes) derived from Dutch language roken. Smoking is the activity of smoking cigarettes (tobacco). The danger of smoking has been widely discussed and recognized. Research conducted by scientists has provided evidences of the dangers of smoking and that there is a decline in the lung functions of smokers and the people surrounding. World Health Organization has estimated that in 2020, the diseases caused by smoking will lead to the death of about 8, 4 million people in the world and half of them are from Asia. It is estimated that in 2013 , around $80 \%$ of the diseases caused by smoking will exist in countries with low and middle income [5-7].

Cigarette smoke contains more than 4,500 chemicals that have various kinds of toxic, mutagenic and carcinogenic effect. The contents and concentrations of the chemicals are various in different brands of cigarettes. Cigarette smoke produces various components of cellular and extracellular compartment ranging 
from water-soluble particles and gases. The substances that have adverse effects are nicotine, ammonia, carbonmonoxide, carbondioxide, formaldehyde, acrolein, acetone, benzopyrenes, hydroquinone, nitrogen oxide and cadmium. Many substances that are carcinogenic and toxic to the cell, but tar and nicotine have been shown immunosuppressive by affecting the innate immune response of the host and increase susceptibility to infection. Pharmacologic ingredient in tobacco causing addiction is nicotine. It is solid and easily absorbed by the mucous membranes of the nose, mouth and lung tissue. The main criteria for determining the drug addiction is that drug users are always encouraged to use drugs. There is a psychoactive effect that can be found in them and they are accustomed to use the drugs. The higher level of tar and nicotine, the bigger effects on the immune system are $[8]$.

Tobacco has been cited as the cause of death globally for killing more than 5 million people worldwide each year. Smoking is an important risk factor for cardiovascular disease as well as 5 other major causes of death worldwide, namely cerebrovascular, lower respiratory tract infection, COPD, tuberculosis, and respiratory cancers [9]. Smoking remains the major cause of preventable death in the world. Quitting smoking is associated with a significant benefit on the individual and social level. Given the prevalence of smoking, a great effort has been directed to develop interventions to help smokers quitting smoking. However, interventions to stop smoking have various results. Quitting smoking is necessary to reduce morbidity and mortality, but many smokers have troubles stopping the habit. Efforts with psychosocial interventions and the use of drugs have been used for that purpose [10].

It is reported that the use of tobacco by smoking is more dangerous than any other ways and active smokers give rise to a variety of disease than nonsmokers. However, substantially passive smokers also contribute to cause various diseases. Approximately 1.1 billion people are smoking worldwide, more than $80 \%$ are in low and middle income countries. China has the largest production and consumption of tobacco in the world. In many countries, about $49 \%$ men and $8 \%$ women over 15 years old are smoking, it is in contrast to $37 \%$ men and $21 \%$ women who come from high income countries. More than $60 \%$ smokers live in only 10 countries, namely China, India, Indonesia, Russia, the United States, Japan, Brazil, Bangladesh, Germany and Turkey. The consumption of per adult per day (number of cigarettes smoked per day are divided by the population of smokers and non-smokers) has declined by more than $50 \%$ in the last $2-3$ decades in America, Canada, France and other high income countries. In contrast, smoking prevalence in men has increased sharply in countries with low and middle incomes as China and Indonesia. Marked improvement has occurred in young males. The differences between women and men are associated with differences in tobacco use, in terms of use prevalence, the use of shorter duration or use frequency that is lower in women. The research in Brazil obtained the real decline in smokers in low income communities [11-13]

In addition to HIV/ AIDS, tobacco smoking is the major cause of death increasing rapidly. It is estimated that smoking will cause about 10 million deaths in adults in 2030 and most of the increase in tobaccorelated deaths will take place in Asia, Africa and South America. A study conducted in Oslo showed that light smokers of 1-4 cigarettes per day was still able to increase mortality $[9,14,15]$.

In overall, although smoking rates have declined over the years, more than one fifth of Americans are smokers. In 2004 approximately $21 \%$ of adults and $22 \%$ of high school students were smokers. Consequently, smoking has caused premature death in America. Each year, as many as 438,000 Americans are estimated to die due to smoking or passive smoking. Estimated costs associated with smoking are medical and lost productivity costs exceeding 167 billion U.S. dollars per year [8].

\subsection{Tuberculosis}

Tuberculosis is a disease caused by the infection of Mycobacterium tuberculosis complex and becomes an important public health problem in Indonesia. M. tuberculosis has rod-shaped, $5 \mu$ length and $3 \mu$ width, do not form spores and belongs to aerobic bacteria. Mycobacteria can be given staining like other bacteria, for instance using the Gram staining. But once stained by Gram staining, the colour cannot be removed with acid. Therefore, the mycobacteria is called Acid Bacillus (AFB). In the cell wall of mycobacteria, fat is associated with arabinogalactan and peptidoglycan underneath. This structure reduces the permeability of cell walls, thereby reducing the effectiveness of antibiotics. Lipoarabinomannan of other molecules in the cell wall of mycobacteria play a role in the interaction between host and pathogen, causing M. Tuberculosis can survive within macrophages [16].

In 1992, WHO declared TB as a global emergency. Currently, tuberculosis mainly attacks productive age people and increases mortality, especially in developing countries. In 2010, it was reported the incidences of tuberculosis in the world wre at 8.8 million (from 8.5 to 9.2 million), 1.1 million (0.9-1.2 million) deaths due to HIV-negative TB plus 0.35 million (0.32 to 0.39 million) TB sufferers with HIV-positive. In 2009, it was reported 2.4 million new cases (3.3 million women), 133 cases/100.000 population with HIV sufferers equal to 1.1 million people. Deaths due to TB infection were 1.7 million people (380,000 women), including 380,000 HIV sufferers, in accordance with 4700 deaths per year and became the third leading cause of death in women 
aged 15-44 years old. Eighty percent of active TB cases were found in 22 developing countries, most of them were in Asia (with 55\% cases in the world) and Africa (30\%). Approximately 5\% of the global burden of TB cases are now resistant to several drugs. In Russia, it was reported that TB cases resistant to drug accounted for over a fifth of all new TB cases in 2008. In 2008, as many as 1.4 million people living with HIV had active TB. HIV positive people more likely to become infected tend to be resistant to drugs and increase the mortality rates. India ranks the first of TB patients in the world (1.6 to 2.4 million). It accounts for about one fifth of the total number of cases in the world with a mortality rate of $17.6 \%$ and $3.5 \%$ of the total deaths. The next is China (1.1 to 1.5 million), South Africa ( 0.4 to 0.59 million), Nigeria ( 0.37 to 0.55 million) and Indonesia ( 0.35 to 0.52 million). In the United States, it was reported a significant decrease, in 1945 it was reported 73/100.000 population, in 1993 was 9.0/ 100,000 population and in 2009 there was 3.8/100,000 population. In Nigeria, it was reported the incidence of TB equal to $14.4 \%$ and estimated 380,000 (9293/100.000 population) of new TB cases each year, much bigger than the standard recommended by WHO equal to 3\% [16-18].

TB diagnosis can be established based on clinical symptoms, physical examination, bacteriological examination that have important meaning in establishing the diagnosis. Material for this bacteriological examination can be derived from the phlegm, pleural fluid, cerebrospinal fluid, bronchial washings, gastric washings, broncho alveolar lavage/ BAL, urine, faces and biopsy tissue (including fine needle biopsy/ BJH). Radiological examination with standard examination of chest X-ray of PA (posteroanterior) and other radiology examinations are lateral photos, top-lordotic, oblique or CT-Scan. Other supporting examinations are such as pleural fluid analysis, tissue histopathological and blood examination. Clinical symptoms of TB can be divided into 2 groups, namely local symptoms and systemic symptoms. If the infected organ is the lung, the local symptom is respiratory symptom (Local symptoms in according to organs involved). Respiratory symptoms are such as cough \pm 2 weeks, coughing up blood, shortness of breath and chest pain. These respiratory symptoms are highly various, ranging from no symptoms until the symptoms quite severe depending on lesion area. Sometimes patients are diagnosed during medical check up. If the bronchus is not involved in the disease process, the patients may not suffer cough symptoms. The first cough occurs due to bronchial irritation, and the next coughs are needed to get rid of phlegm out. The systemic symptoms caused by TB infection are fever, malaise, night sweats, anorexia and weight loss. On pulmonary tuberculosis, the acquired abnormalities depend on the area of lung structural abnormalities. At the beginning (early) development of disease, in general it is not (or difficult) found abnormalities. Pulmonary abnormalities are generally located in the superior lobe area, especially apex and posterior segments (S1 and S2), as well as inferior lobe apex area (S6). On physical examination, it can be found, among others, bronchial breath sounds, amforik, decreased breath sounds, wet rhonchi, withdrawal signs of lung, diaphragm and mediastinum. At TB pleurisy, physical examination abnormalities depend on the amount of fluid in the pleural cavity. On percussion it is found dullness, on weakened breath sounds auscultation till no sound on the sides containing liquid. At TB lymphadenitis, the enlargement of lymph nodes is visible, commonly in the neck (think of the possibility of tumor metastasis), sometimes in the armpit area. The enlargement can be a "cold abscess ".

\section{Analysis Method}

Smoking has demonstrated a broad impact on the host immune mechanisms. There are a lot of controversy studies because of differences in smoking history, genetic susceptibility, social economy, sports, nutrition, air humidity and works that can modify diseases. Respiratory epithelium is the first line of defense against harmful environment agents and do the protection by sweeping particles out of the mucus layer, phagocytosis also recruit other immune cells. Smoking is directly harmful to the integrity of physical barriers, increase the permeability of respiratory epithelium and disrupt mucociliary clearance. Acute cigarette smoke exposure results in suppression of the respiratory epithelium and chronically may result in inflammation and damage, causing epithelial cell shape changes $[1,19]$.

In the lungs, cigarette smoke has both proinflammatory and immunosuppressive effects on the immune system. Macrophages have a strategic role in alveolar. Alveolar macrophages have a key role in undermining and eliminating microbial agents at the beginning when there is an infection. Smoking also increases the number of alveolar macrophages and epithelial cells and activate them to produce pulmonary circulation micro proinflammatory, Reactive Oxygen Species (ROS) and proteolytic enzymes, thereby providing a cellular mechanism linking smoking with inflammation and tissue damage. Similarly, smoking affects the ability of alveolar macrophages to do phagocytosis on bacteria and apoptosis cell. At the same time, cigarettes also disrupt the natural defense mechanism mediated by macrophages, epithelial cells, dendritic cells (DCs), and natural killer cells (NK ) so that it increases the risk, severity and duration of infection. Effects of cigarette in conjunction with the increase of diseases to become more severe are characterized by impaired ability of macrophages to kill bacteria or virus, loss of ability to clear dead cells, degradation and modification chemically of the extracellular matrix, increased TCD8 cell retention and induction of Interleukin-17 (IL-17) as the secretion effectors of $\mathrm{T}$ cell. After long term exposure to cigarettes, lymphocytes aggregation areas with $\mathrm{T}$ cell 
and $\mathrm{B}$ cell can be formed on those sides, helping the production of pathogenic antibodies and causing autoimmune disease. The loss of mucosal defense may result in bacterial colonization as happens in $30 \%$ longterm smokers with COPD [19].

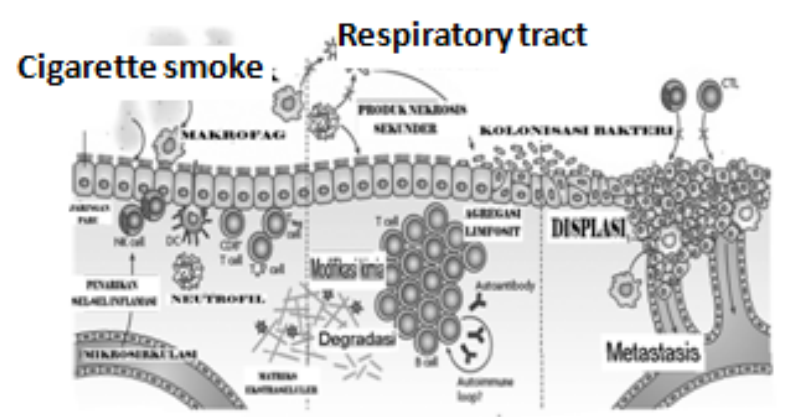

Figure 1. Immune system disorders in the lungs due to smoking Quoted from [19]

Evidences suggest that NK cells has a role in innate defense against microbial agents and anti-tumor protection. This is carried out by direct cytotoxicity triggering apoptosis, proinflammatory cytokines and the release of chemokines. Some studies show that they can reduce the number of smokers and reduce activation in smokers than nonsmokers. Exposure to cigarette smoke weakens the cytotoxic activity and cytokine production of NK cells in humans and mice, thus, the defect relationships of NK cells lead to increased risk of infection and cancer. Dendritic cells (DCs) lung is the most potent antigen cells and necessary for the initiation of $\mathrm{T}$ cell and thought to have a high susceptibility to cigarettes because of its position within the lumen and directly under the pulmonary epithelium. Clinical studies show that the number of DCs is reduced in most of the respiratory tract of COPD patients who smoke. After quitting smoking, the number of DCs are increasing and similar to controls of healthy people who are not smoking. Of a study in animals, it is reported the decreased number of DCs depend on the type of cigarette exposure system. Autoimmune processes play a role in the arising of smoking related with diseases. Smoking may also reduce the level of all classes of immunoglobulin except Ig E. On a study with experimental animals, it is obtained that the antibody responses on various antigens is reduced significantly due to chronic exposure to cigarette smoke [19]

\section{Analysis Result: Relationship Between Smoking And Tuberculosis}

The relationship between smoking and TB were first reported in 1918. The exact mechanism that correlates smoking with TB is not fully understood, but there are a lot of evidences of declining respiratory tract defense that affect susceptibility to TB infection in smokers. Trachea, bronchi and bronchioles that form the respiratory tract that supply air to the lungs provide the first line of defense by preventing TB germs to reach the alveoli. Smoking is proven to interfere with mucociliary clearance. In pulmonary alveolar macrophages constituting a primary defense, there is a function decline in phagocytosis and kill germs in individuals who smoke, as reported in diabetes. Smoking has been found to be associated with decreased levels of proinflammatory cytokines that are released. These cytokines are essential for early responses of local defense to bacterial infection including TB. In various studies indicate that the quantity and duration of active smoking influence the risk of TB infection, while on passive smoking it is associated with increased incidence of TB in children and young age $[4,20,21]$.

Of the retrospective study conducted in Dublin on 160 cases between April 2007 and April 2008, it was found that smoking was significantly related to TB germ conversion time elongation in patients who were on anti-TB drug therapy. Other studies showed increased rates of recurrence of TB patients who smoked [22, 23]. Control case study in 111 patients of BTA positive with 333 controls performed in India on September 2004 to August 2005, it was found the increased incidence of TB infection in smokers equal to 3.8 times compared to non smokers and was associated with the number of smoking, body mass index and social economy status. In this study, the duration and number of cigarettes also affected the development of TB [24].

In America there are a number of difficulties in assessing smoking as a risk factor for TB infection. Among the most important is the low prevalence of TB infection in the general population and smoking rates have declined. In America, smoking is becoming increasingly concentrated in populations with low socioeconomic leading to other risk factors for TB like HIV, homelessness, alcohol drinkers, and heterogeneity of TB risk inter-groups. Currently more than $50 \%$ TB patients in the United States come from various countries in various stages of tobacco epidemic and risk factors for TB that are different between migrants and the nativeborn Americans. A study of indigenous peoples and migrants in Australia show that the TB incidence rates tend 
to be higher on the natives, it is related to socio-economic, health care standards, and the habit of smoking which is high $[9,25]$.

Although some studies have shown the relationship between smoking and TB, many of them are based on infection or mortality rates. These studies have various limitations such as control case designs or crosssectional sample size that is small, and lack in socio-economic data, alcohol, HIV infection and other influential factors. In Hongkong, smoking and TB are two common conditions. Smoking prevalence is much higher in men than in women. More than $20 \%$ adult males are active smokers and TB incidence equal to 100 per 100,000 population per year and more common in men aged above 65 years old. Smoking is associated with increased susceptibility to influenza and TB. From the studies using experimental mouse animal with rats receiving exposure to M. TB aerosolly, it was found that the interferon ${ }^{3}\left(\mathrm{IFN}^{3}\right)$ production by T cells would decrease with a decrease in transcription factors that regulate the expression of IFN ${ }^{3}$ in mice exposed to cigarette. This study provided the first demonstration that exposure to cigarette smoke directly inhibited $\mathrm{T}$ cell responses to $\mathrm{M}$. TB and influenza virus on animal physiology so that it increased the susceptibility to both pathogens $[26,27]$.

Smokers have a extremely high mortality rates from tuberculosis, as many as nine times greater than those who have never smoked, but once they stop, the risk is substantially reduced and similar to those who never smoked. Quitting smoking has benefits for smokers far beyond reducing the risk of TB, but a good tobacco control can affect the mortality rate of TB and reduce the burden public health and by quitting smoking can reduce nearly one third of deaths from TB. TB risk can be reduced by nearly two-thirds if someone quitting smoking becomes strong evidence of the important role of smoking in TB control, such as smoking was responsible for more than one-third of TB deaths in Taiwan (37.7\%). Controlling tobacco succeeded in reducing smoking in form of affecting mortality rates of TB and reducing nearly a third (30.7\%) of the public health burden that had long interfered the residents of Taiwan. This is a big health impact on enhancing the public 's health, especially when applied to countries such as China, India that have the prevalence of smoking and the higher incidence of TB. Quitting smoking has been shown to reduce the incidence of TB, so it is needed an increase in knowledge and research on the benefits of quitting smoking to reduce mortality rates. With two thirds of Chinese men smoking and about three million cases of TB, thus, the good prevention and treatment guidelines need to carry out. Smoking substantially exacerbates the risk of death in those with a history of TB infection. The mortality in patients who were smoking was reported by $61 \%$ in India and $32.8 \%$ in Hong Kong $[21,28]$. Of a study correlating the effects of vitamin on TB patients who smoke, it was obtained that vitamin $\mathrm{E}$ supplement caused temporary increase in the incidence of TB among heavy smokers with high dietary intake of vitamin E. Vitamin A and E do not increase the immune response in TB sufferers who smoke. This study finds that none of the two compounds can increase resistance to TB among men smokers. Instead, vitamin E seems to increase the incidence of TB in those who smoke heavily and have gained intake dietary of vitamin $\mathrm{C}$ equal to $90 \mathrm{mg} /$ day or more [29].

\section{Conclusion}

From the analysis result, the effects of smoking habit on the development of tuberculosis disease are: (1) Smoking and TB remain a significant health problem in both developed countries and developing countries, (2) Cigarette smoke has the effects of both pro-inflammatory and immunosuppressive in the immune system of respiratory tract, (3) Smoking increases the infection risk of Mycobacterium tuberculosis, the risk of disease progression and death in patients with TB, (4) Quitting smoking plays a role in global tuberculosis control and reduces mortality in patients with $\mathrm{TB}$.

\section{Reference}

[1]. Bat es MN, Khalakdina A, PaI M, Chang L, Lessa F, Smit h KR. Risk oft uberculosis from exposure t o tobacco smoke. Arch Intern Med. 2007;167:335- 42.

[2]. Zainul Z. Dark nights behind the white clouds- risk of tobacco smoking on human health besides the oral health ang malignancy. Exceli Journal.2011;10:69- 84 .

[3]. World Health Organizat ion. WHOreport on the Global tuberculosis control report .(Online); 2011(cited 2011 November 17). Avai 1 abl e from: URL: ht t p// www.whql i bdoc.who.i nt / publ i cat i ons/ 2011 / $9789241564380 \_$eng.pdf.

[4]. Leung CC, Lam TH, Ho KS, Yew WW,Tam CM, Chan WM, et al. Passive smoking and tuberculosis. Arch Int ern Med. 2010;170:287-92.

[5]. Aditama T.Y Yout h tobacco Indonesian experience, Mumbai, India; Indonesia smoking control foundation.2009.

[6]. Ross J, Ehrlich RI, Hnizdo E, White N, Churchyard GJ. Excess lung function decline in gold miners following pulmonary tuberculosis. Thorax. 2010;65:1010-5.

[7]. PDPI. Berhent i merokok. Pedoman penatalaksanaan unt uk dokt er Indonesia. Perhimpunan Dokt er Paru Indonesia. Jakarta 2011.p 4- 12

[8]. Mehta1 H, Nazzal K, Sadikot1 R. Cigarette smoking and innate immunity. Inflamm ResJ. 2008;57:497-503.

[9]. Gi acomo M, Davi dson PM, Penelope A. Abbot t P, Davison P, Moore L, Thompson S. Smoking cessat ion in indigenous populations of Australia, New Zealand, Canada, andthe United Stat es: Element s of effect ive int ervent ions. Int. J. Environ. Res. Public Health. 2011;8: 388- 410.

[10]. Mills EJ, Wu P, Spurden D, Ebbert J,Wilson K. Efficacy of pharmacot herapi es f orshort - $t$ erm smoki ng abstinance: A systematic review and meta- analysis. Harm Reduction Journal. 2009; 6:25. 
[11]. WHO. Gl obal Tuberculosi s cont rol. WHO/HTM/TB/ 2008.393. Geneva: World Health Organizat ion;2008. Availableonlineat http://www.who.int/tb/publications/ globalreport/2008/en/index.html(Accessed September9, 2011).

[12]. Pet o R, Lopez A, Boreham J, Thun M. Mortality from smoking in developed countries, 1950-2005. University of Oxford Clinical Trial Service Unit [online], http:// www.ctsu.ox.ac. uk/ tobacco (2009).

[13]. Salma K, Chiang C, Enarson DA, Hassmiller K, Fanning A, GuptaP, et al. Tobacco and tuberculosis: aqualitative syst ematic review and meta- analysis. International Journal of Tuberculosis and Lung Disease.2007; 1049-61.

[14]. Wang J, Shen H. Review of cigarette smoking and $t$ uberculosi $s$ in China: int ervent $i$ on is needed for smoking cessat ion among $t$ uberculosis patients. BMC Public Health. 2009; 9:292.

[15]. Bjartveit K, Tverdal A. Health consequences of smoking 1-4 cigarettes per day. Tobacco Control. 2005;14:315-20.

[16]. PDPI. Tuberkul osi s. Pedoman di agnosi s dan penatalaksanaan di Indonesia. Perhimpunan Dokter Paru Indonesia. Revisi pert ama Juli 2011.Jakarta: 9- 19

[17]. Udwadia F, Finto L. Why stop Tb isuncomplete without quit smoking. Indian J ChestAllied Sci.2011;53;9- 10.

[18]. Amoran O, Osiyale O, Lawal K. Pattern of default among tuberculosis patients on directly observed t herapy in rural primary health carecentresin Ogun State, Nigeria. Journal of InfectiousDiseasesand Immunity.2011;3(5): 90- 5.

[19]. Stämpfli M, Anderson G. How cigarette smoke skews immune responses topromot e infection, lung disease and cancer. Immunology. 2009; 9: 34-9

[20]. Lin HH, Ezzati M, Murray M. Tobacco smoke, indoor air pollution and tuberculosis: A systemat ic review and meta- analysis. PLoSMedicine.2007:173-89.

[21]. Wen CP, Chan TC, Chan HT, Tsai MK, Cheng TY, Tsai SP. Ther reduct ion of Tuberculosis risks by smoking cessation. BMC Infect Dis. 2010;10:156.

[22]. Siddiqui UA, O'Toole M, Kabir Z, Qureshi S, Gibbons N, KaneM,et al. Smokingprolongstheinfectivity of patients with tuberculosis. Ir Med J.2010; 103(9):278-80.

[23]. Batista J, Pessoa M, XimenesRA, Rodrigues L. Smoking increasestherisk of relapseafter successful tuberculosis treat men. Int J Epidemiol. 2008;37 (4):841- 51.

[24]. Suryakant PR, R. Garg S, Dawar S, AgarwalS. A case- control study of tobacco smoking and tuberculosis in India Ann Thorac Med. 2009;4(4): 208-10.

[25]. Davies P, Yew W W, Ganguly D, Davidow AL, Reichman L, Dheda K, et al. Smoking and t uberculosi s: $t$ he epidemiological association and immuno pathogenesis. Transactions of the royal society of tropical medicine and hygiene . $2006 ; 291-8$.

[26]. Leung C, Li T, Lam TH, Yew WW, Law WS, Tam CM, et al. Smoking and tuberculosisamong theelderly in Hong Kong. Am J Respir Crit Care Med. 2004;170: 1027-33.

[27]. Feng Y, Kong Y, Barnes PF, Huang F, Klucar P, Wang X, et al . Exposure t o ci garet t e smoke i nhibi t s t he pulmonary T-Cell response $t o$ influenza virus and Mycobacterium tuberculosis infection and immunity. 2011;79(1): $229-37$.

[28]. Lin HH, Murray M, Cohen T, Colijn C, Ezzati M. Effects of smoking and solid- fuel use on COPD, lung cancer, and tuberculosis in China: a time- based, mult iple risk fact or, modelli ng st udy.Lancet . 2008; 372(9648): 1473-83.

[29]. Hemila H, Kaprio J. Vitamin E supplement ation may transient ly increase tuberculosis risk in males who smoke heavily and have high dietary vitamin intake. British Journal of Nutrition. 2008;100:896-902. 